\title{
Correspondence
}

\section{A systematic review of computational fluid dynamics in type B aortic dissection}

Zhonghua Sun ${ }^{1}$, Thanapong Chaichana ${ }^{2}$

1. Department of Medical Radiation Sciences, Curtin University, Perth, Western Australia, 6845, Australia

2. The Hamlyn Centre for Robotic Surgery, Imperial College London, UK

\section{Corresponding author:}

Professor Zhonghua Sun, Department of Medical Radiation Sciences, Curtin University, GPO Box, U1987, Perth, Western Australia 6845, Australia

Tel: +61-8-9266 7509

Fax: +61-8-9266 2377

Email: z.sun@curtin.edu.au 
Currently, there is a lack of appropriate clinical consensus as to whether medical treatment, or surgical intervention or endovascular stent graft repair is applied to manage patients with type B aortic dissection. This is due to the fact that hemodynamics is considered to play a critical role in the formation and progression of type B aortic dissection, however, accurate mechanical and hemodynamic characteristics of type B dissection are not fully understood. Despite rapid developments of imaging modalities including CT and MRI and resultant high diagnostic accuracy in the anatomic assessment of aortic dissection, no imaging criteria can reliably select the most appropriate treatment option for individual patients with type B aortic dissection. This leads to a growing interest in the use of patient-specific computational modelling and simulation to assist clinical decision making in type B dissection. In recent years, computational fluid dynamics (CFD) has gained a lot of interest as a complementary tool for improving understanding of pathogenesis and disease progression in cardiovascular disease [1, 2]. CFD simulations based on patient-specific models may provide insight into the biomechanical behaviour of blood flow in the type B dissection, allow quantitative analysis of hemodynamic patterns and predict clinical progression of aortic dissection, although its clinical value remains to be verified. The purpose of this systematic review is to evaluate the applications of CFD simulations in type B dissection, in particular, determine its clinical significance in aiding prediction of dissection degeneration and progression.

This analysis was performed in accordance with the PRISMA guidelines. Pubmed/Medline and Scopus databases were searched until January 25, 2016 using the following search keywords: Computational fluid dynamics in aortic/type B dissection, computational simulations and analysis in aortic /type B dissection, computational modelling and analysis in aortic/type B dissection. Eligible studies included evaluation of CFD in type B dissection based on patient-specific models derived from CT or MRI images. Studies using idealized models or in vitro phantom experiments were excluded. Potential references were searched 
and evaluated by two independent reviewers to determine if they met the inclusion criteria, with uncertainty or disagreement resolved by consensus. Data were extracted from individual studies with a focus on the number of cases, study focus of CFD simulations and key findings. A total of 54 studies were initially identified. Of these, 37 were excluded for not meeting the inclusion criteria. Of 17 eligible studies, 3 studies were further excluded due to repetitive reports by the same research group, and only the most recent studies from each group were used, leading to 14 studies included in the analysis [3-16]. Table 1 shows characteristics of these eligible studies. Although multiple studies were reported by three different research groups [5-11, 14, 15], each report focused on different aspects of CFD simulations addressing variable simulated scenarios or clinical aspects, they were included in the analysis. Patientspecific CFD simulations based on a single patient's images were reported in 11 studies (with use of CT and MRI data in 6 and 5 studies, respectively). In the remaining three studies, CFD simulations were performed based on 3, 8 and 14 cases, respectively.

Findings of these CFD modelling and simulations can be summarized into the following three areas: First, patient-specific CFD simulations successfully captured the complex regions of hemodynamic flow and were able to demonstrate hemodynamic changes in both true lumen (TL) and false lumen (FL) in terms of flow patterns, velocity, wall pressure and wall shear stress (WSS). In particular, the two hemodynamic parameters derived from WSS which included time-averaged WSS (TAWSS) and oscillatory shear index (OSI) were analysed and reported in more than half of the studies. High WSS/TAWSS was observed at the entry tear region (Fig 1), while flow patterns in the FL were shown to be vortical structures, and more complicated and disorganised that those in the TL. This phenomenon is more apparent in the rapidly expanding dissection aneurysm (Fig 2). In comparison with the in vivo flow structures obtained by the standard reference, phase contrast MRI (PC-MRI), CFD simulations showed good agreement with the PC-MRI. Second, presence of exit or re-entry tear was found to 
have an effect on the hemodynamic changes in the type B dissection. One study [8] simulated virtual occlusion of entrance tear (simulating thoracic endovascular aortic repair-EVAR) and exit tear (simulating FL thrombosis) based on MRI data. Their results showed that pressure was decreased in the FL following EVAR occlusion of the entry tear and partial thrombosis in the FL was found to result in increased FL pressure, thus presenting potential risk of FL expansion and lumen rupture. Another study [14] simulated additional re-entry tear of 10 and $16 \mathrm{~mm}$ diameter based on CT data, and discussed hemodynamic effects of these re-entry tears in type B dissection. Although presence of additional re-entry tear did not change the direction and magnitude of the blood flow, the extra re-entry tear was noticed to provide an extra return path for blood to the TL and outflow path into the FL during systole and diastole, respectively. Third, CFD simulations in type B dissection before and after EVAR were investigated to quantify changes in hemodynamic parameters. Although simulations were based on a single case with 1 year follow-up [9], researchers in that study performed quantitative analysis of WSS changes, with significantly lowered WSS seen in the FL (Fig 3). Large WSS magnitudes were eliminated following EVAR, and antegrade flow in the FL was also eliminated due to occlusion of the entrance tear by stent graft placement.

This systematic review shows that CFD is a feasible technique for revealing hemodynamic features that represent realistic physiological conditions in type B dissection. Hemodynamic parameters such as flow pattern, pressure and WSS are difficult to be measured in vivo, and cannot be obtained with imaging techniques, but can be defined by CFD modelling and simulations. WSS is widely known to play a major role in initiation, progression and destabilization of atherosclerotic cardiovascular disease [1, 2], and this has been confirmed in this analysis as WSS (or TAWSS) is the key factor analysed in these studies. WSS rather than pressure is also found to play a key role in the false lumen dilatation. Since false lumen patency is regarded as a primary predictor of aneurysm dilatation in type B dissection, CFD 
simulations could predict false lumen progression and clinical outcomes in individual patients suffering from type B dissection, although further studies of CFD simulations based on a large cohort are warranted. 


\section{References}

[1] Morris PD, Narracott A, von Tengg-Kobligk, et al. Computational fluid dynamics in cardiovascular medicine, Heart, 102 (2016):18-28.

[2] Sun Z, Xu L. Computational fluid dynamics in coronary artery disease, Comput. Med. Imaging. Graph, 38 (2014): 651-663.

[3] Alimohammadi M, Sherwood JM, Karimpour M, Agu O, Balabani S, Diaz-Zuccarini V. Aortic dissection simulations models for clinical support: fluid-structure interaction vs. rigid wall models, Biomed. Eng. Online, 14(2015):34. doi: 10.1186/s12938-015-0032-6.

[4] Chen D, Muller-Eschner M, von Tengg-Kobligk H, et al. A patient-specific study of type B aortic dissection: evaluation of true-false lumen blood exchange, Biomed. Eng. Online, 12(2013): 65.

[5] Cheng Z, Tan FPP, Riga CV, et al. Analysis of flow patterns in a patient-specific aortic dissection model, J. Biomed. Eng, 132(2010): 051007.

[6] Cheng Z, Juli C, Wood NB, et al. Predicting flow in aortic dissection: Comparison of computational models with PC-MRI velocity measurements, Med. Eng. Phys, 36(2014):1176-1184.

[7] Cheng Z, Wood NB, Gibbs RGJ, Xu XY. Geometric and flow features of type B aortic dissection: initially findings and comparison of medically treated and stented cases, Ann. Biomed. Eng, 43(2015):177-189.

[8] Karmonik C, Bismuth J, Shah DJ, Davies MG, Purdy D, Lumsden AB. Computational study of haemodynamic effects of entry- and exit-tear coverage in a DeBakey type III aortic dissection: technical report. Eur. J. Vasc. Endovasc. Surg, 42(2011):172-177.

[9] Karmonik C, Bismuth J, Davies M, et al. A computational fluid dynamic study preand post-stent graft placement in an acute type B aortic dissection, Vasc. Endovasc. Surg, 45(2011):157-164. 
[10] Karmonik C, Partovi S, Muller-Eschner M, et al. Longitudinal computational fluid dynamics study of aneurysmal dilatation in a chronic DeBakey type III aortic dissection, J. Vasc. Surg, 56(2012):260-263.

[11] Karmonik C, Muller-Eschner M, Partovi S, et al. Computational fluid dynamics investigation of chronic aortic dissection hemodynamics versus healthy aorta, Vasc. Endovasc. Surg, 47(2013):625-631.

[12] Shang EK, Nathan DP, Fairman RM, et al. Use of computational fluid dynamics studies in predicting aneurysmal degeneration of acute type B aortic dissections, J. Vasc. Surg, 62(2015):279-284.

[13] Tse KM, Chiu P, Lee HP, Ho P. Investigation of hemodynamics in the development of dissecting aneurysm within patient-specific dissecting aneurismal aortas using computational fluid dynamics (CFD) simulations, J. Biomech, 44(2011):827-836.

[14] Wan Ab Naim, Ganesan PB, Sun Z, et al. The impact of the number of tears in patient-specific Stanford type B aortic dissecting aneurysm: CFD simulation, J. Mech. Med. Biol, 14(2014):1450017.

[15] Wan Ab Naim, Ganesan PB, Sun Z, et al. Prediction of thrombus formation using vortical structures presentation in Stanford type B aortic dissection: a preliminary study using CFD approach, Appl. Math. Model, (2015) (Epuab ahead of print): doi:10.1016/j.apm.2015.09.096.

[16] Zhang Y, Lu Q, Feng X, et al. A pilot study exploring the mechanism involved in the longitudinal progression of acute aortic dissection through computational fluid dynamic analysis, Cardiology, 128(2014):220-225. 
Figure and figure legends

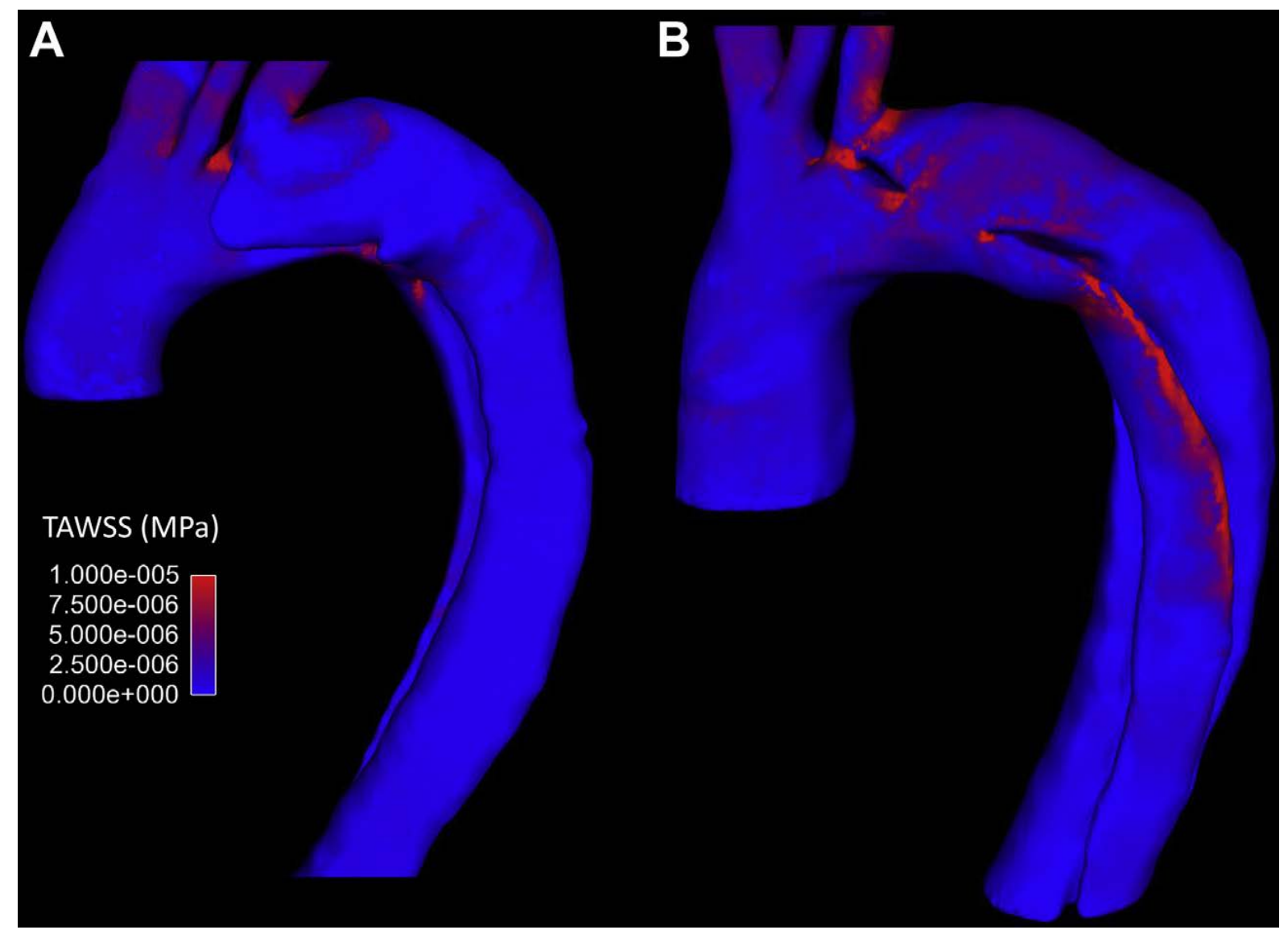

Figure 1. Time-averaged wall shear stress (TAWSS) plotted on the aortic surface. Note the increased TAWSS along the true lumen in the dissection in (B) as well as the increased area over which TAWSS is increased compared with the dissection in (A). Reprint with permission from ref 


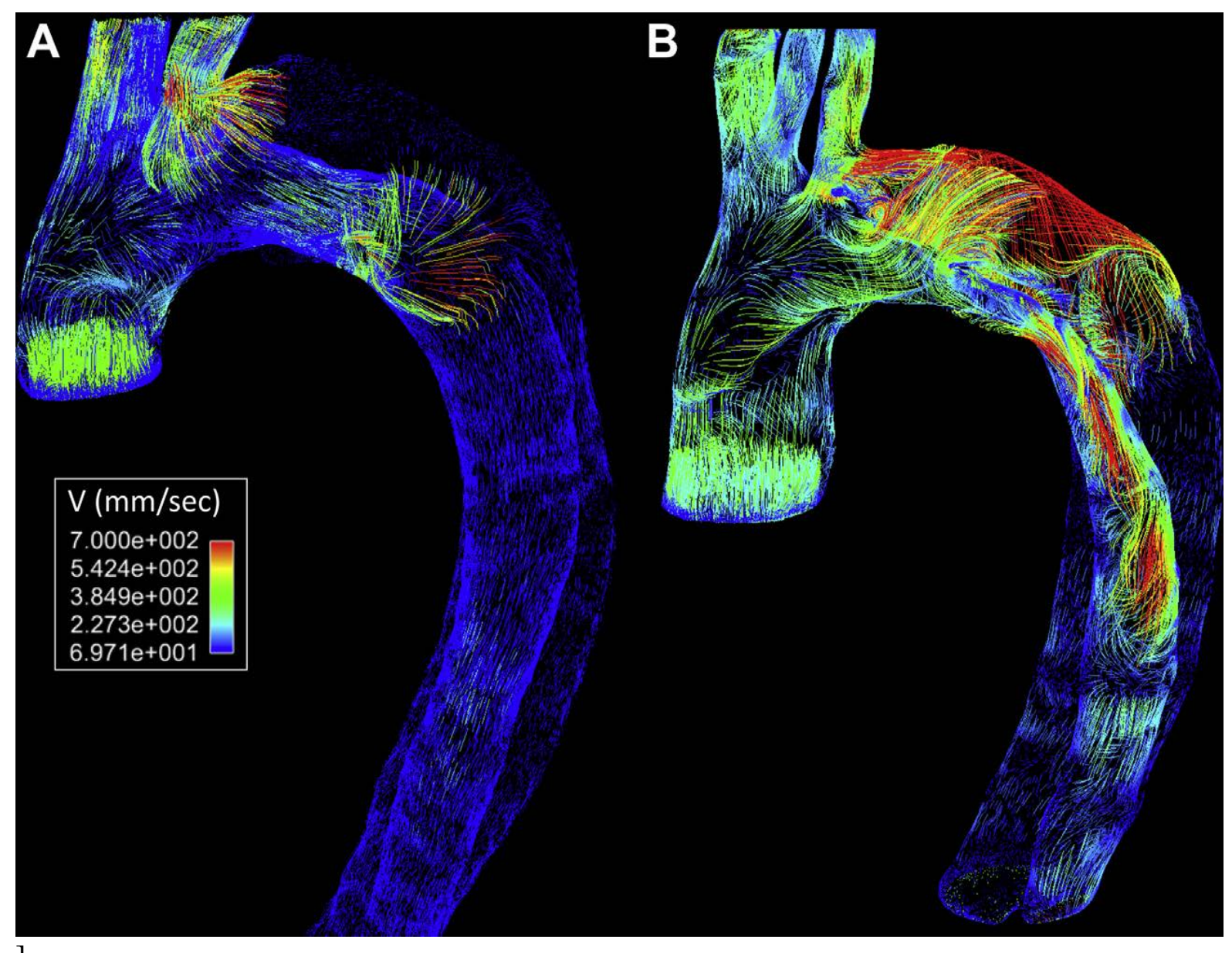

].

Figure 2. Flow velocity maps of the thoracic segments of the aortic dissections in Fig 1 showing the acceleration of blood through dissection tears and its subsequent impingement on the far aortic wall. A, An aortic dissection with a stable transaortic diameter. B, An aortic geometry with rapid expansion showing greater turbulence in the false lumen. Reprint with permission from ref [12]. 


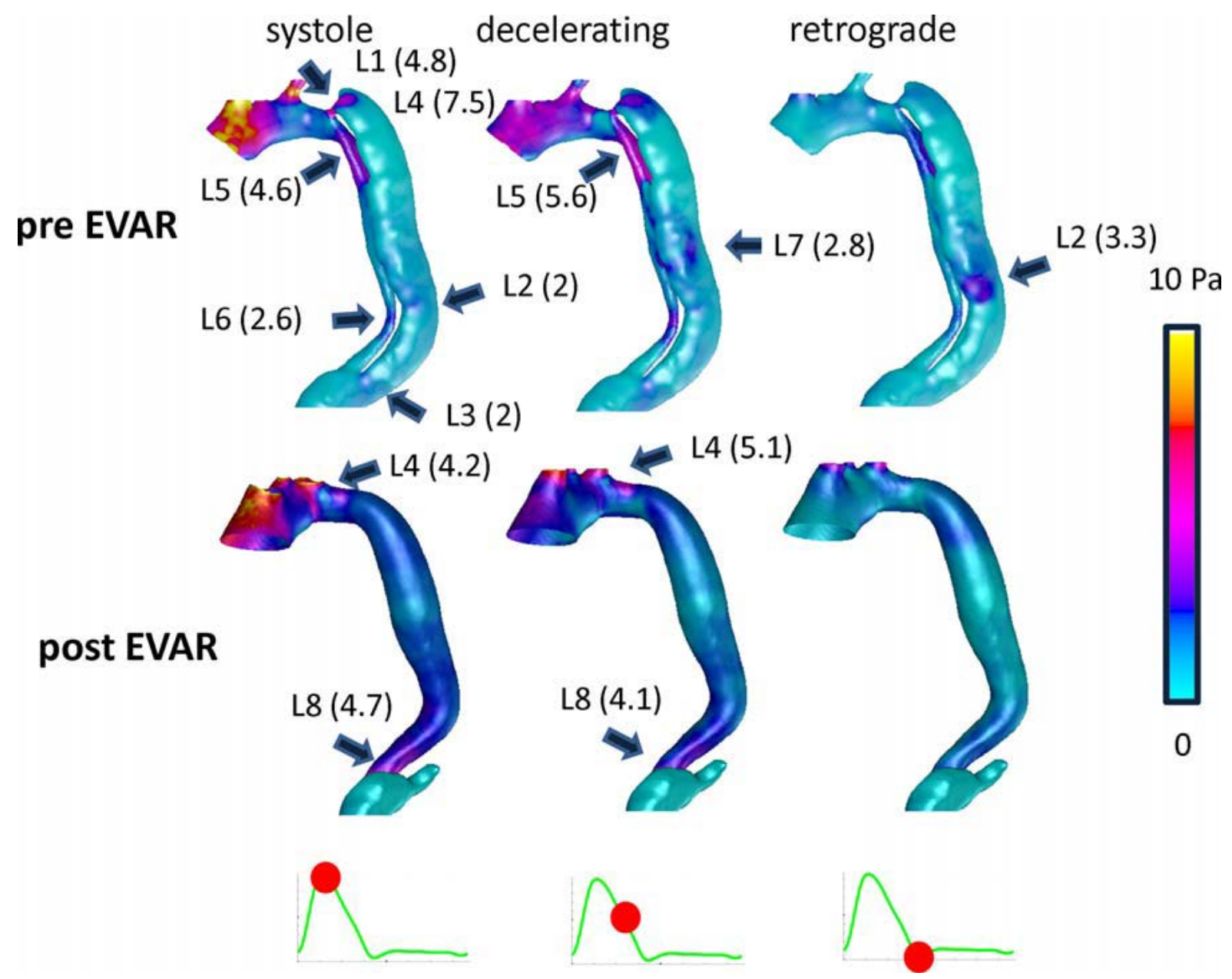

Figure 3. Pseudocolor representation of WSS pre and post EVAR treatment at different times in the cardiac cycle (schematically illustrated at bottom of figure by red marker onto flow waveform in the ascending aorta). Locations of interested are marked by arrows and symbols. L1-location of entry tear in the FL, L2-anterior curvature of the FL, L3-locatioon of re-entry tear in the FL, L4-proximal to the entry tear in the TL, L5-distal to the entry tear in the TL, L6-anterior curvature of the TL, L7-anterior curvature of the FL, L8-proximal to the re-entry tear in the TL. Numbers in parenthesis are WSS values (in Pa) at the designated location. FLfalse lumen, TL-true lumen, EVAR indicates endovascular aortic repair; WSS, wall shear stress. Reprint with permission from ref [9]. 
Table 1: Study characteristics of patient-specific computational fluid dynamics in type B aortic dissection

\begin{tabular}{|c|c|c|c|c|c|}
\hline Authors & Year of publication & No. of cases & $\begin{array}{c}\text { CFD models based on } \\
\text { imaging data }\end{array}$ & $\begin{array}{c}\text { Study focus of CFD } \\
\text { modelling and simulations }\end{array}$ & Key findings \\
\hline $\begin{array}{c}\text { Alimohammadi et al } \\
\text { [3] }\end{array}$ & 2015 & 1 & $\begin{array}{l}\text { CT images of a } \\
\text { 54-year-old female with } \\
\text { acute type B dissection }\end{array}$ & $\begin{array}{c}\text { 3D flow domain combined } \\
\text { with } 3 \text { element Windkessel } \\
\text { models of patient-specific } \\
\text { FSI simulations }\end{array}$ & $\begin{array}{l}\text { TAWSS was increased at the entry } \\
\text { tear and aortic branches, while OSI } \\
\text { was high in the FL around the tear } \\
\text { regions. Pressure was higher in TL } \\
\text { than in FL. FSI models showed } \\
\text { complex flow structures caused by } \\
\text { expansion and contraction of the } \\
\text { vessel wall, which cannot be } \\
\text { captured by the rigid wall model. }\end{array}$ \\
\hline Chen et al [4] & 2013 & 1 & $\begin{array}{l}\text { CT images of } \\
\text { acute type B dissection }\end{array}$ & $\begin{array}{c}\text { Flow } \\
\text { communication/exchange } \\
\text { between TL and FL }\end{array}$ & $\begin{array}{l}\text { Highest velocities occur close to } \\
\text { the entries; vortical flow features } \\
\text { dominate the false lumen, } \\
\text { maximum WSS was found near the } \\
\text { entries, and high turbulent kinetic } \\
\text { energy found in the upper region of } \\
\text { the dissection. }\end{array}$ \\
\hline Cheng et al [5] & 2010 & 1 & $\begin{array}{l}\text { CT images of a } \\
\text { 58-year-old female with } \\
\text { acute type B dissection }\end{array}$ & $\begin{array}{l}\text { Patient-specific model for } \\
\text { detailed analysis of } \\
\text { hemodynamics }\end{array}$ & $\begin{array}{l}\text { TAWSS at the coarctation and } \\
\text { entry tear where velocity is high. } \\
\text { High OSI in the false lumen due to } \\
\text { unsteady flow. Pressure in the TL } \\
\text { was higher than in the FL. High } \\
\text { turbulent flow was seen near the } \\
\text { tear in TL and FL. }\end{array}$ \\
\hline Cheng et al [6] & 2014 & 1 & $\begin{array}{c}\text { MRI images of a } \\
56 \text { year-old male with } \\
\text { acute type B dissection }\end{array}$ & $\begin{array}{c}\text { In vivo velocity comparison } \\
\text { between PC-MRI and CFD } \\
\text { simulations }\end{array}$ & $\begin{array}{l}\text { Good agreement in flow structure } \\
\text { and velocity contours in the } \\
\text { descending aorta in type B }\end{array}$ \\
\hline
\end{tabular}




\begin{tabular}{|c|c|c|c|c|c|}
\hline & & & & & $\begin{array}{c}\text { dissection. Flow patterns in FL } \\
\text { were more complicated and } \\
\text { disorganised. }\end{array}$ \\
\hline Cheng et al [7] & 2015 & 8 & $\begin{array}{l}\text { CT images with follow- } \\
\text { ups: } 8 \text { patients with } \\
\text { acute type B dissection } \\
\text { in } 2 \text { groups, } 4 \text { with } \\
\text { medically treated, } 4 \\
\text { with EVAR treated }\end{array}$ & $\begin{array}{l}\text { Effects of morphological } \\
\text { features of dissected aorta on } \\
\text { hemodynamic changes. }\end{array}$ & $\begin{array}{l}\text { Positive correlation was noted } \\
\text { between size of primary entry tear } \\
\text { and FL flow rate. Highest turbulent } \\
\text { intensity and TAWSS was at the } \\
\text { edge of tear. FL size and patency } \\
\text { are the most important predictors } \\
\text { of poor outcomes. }\end{array}$ \\
\hline Karmonik et al [8] & 2011 & 1 & $\begin{array}{l}\text { MRI images of a 53- } \\
\text { year-old male with } \\
\text { chronic type B } \\
\text { dissection }\end{array}$ & $\begin{array}{l}\text { Simulated } 4 \text { scenarios with } \\
\text { entrance or exit tear present } \\
\text { or occluded, simulating } \\
\text { EVAR and surgical } \\
\text { treatment. }\end{array}$ & $\begin{array}{l}\text { Occlusion of entry tear by EVAR } \\
\text { resulted in decreased pressure in } \\
\text { FL. FL outflow restrictions (partial } \\
\text { thrombosis) were associated with } \\
\text { FL pressure elevation. }\end{array}$ \\
\hline Karmonik et al [9] & 2011 & 1 & $\begin{array}{c}\text { MRI images of a 60- } \\
\text { year-old male with } \\
\text { acute type B dissection } \\
\text { pre- and post-EVAR (at } \\
1 \text { year follow-up) } \\
\end{array}$ & $\begin{array}{l}\text { Quantitative assessment of } \\
\text { hemodynamic changes of } \\
\text { WSS in the FL after EVAR. }\end{array}$ & $\begin{array}{l}\text { Large WSS magnitudes were } \\
\text { eliminated after EVAR, with } \\
\text { maximum WSS in the FL lowered } \\
\text { by a factor of } 2 \text {. }\end{array}$ \\
\hline Karmonik et al [10] & 2012 & 1 & $\begin{array}{l}\text { MRI images of a } 45 \\
\text { year-old male with } \\
\text { chronic type B } \\
\text { dissection (at } 10 \\
\text { months follow-up } \\
\end{array}$ & $\begin{array}{l}\text { Association between aortic } \\
\text { geometries changes and } \\
\text { hemodynamic changes }\end{array}$ & $\begin{array}{c}\text { Wall pressure and WSS decreased } \\
\text { in the FL due to FL dilatation. } \\
\text { Highest WSS was at around the } \\
\text { entry tear. }\end{array}$ \\
\hline Karmonik et al [11] & 2013 & 1 & $\begin{array}{l}\text { MRI images of a } 45 \\
\text { year-old male with } \\
\text { chronic type B } \\
\text { dissection (at } 10 \\
\text { months follow-up) }\end{array}$ & $\begin{array}{c}\text { Comparison of type B } \\
\text { dissection with healthy aorta }\end{array}$ & $\begin{array}{l}\text { At location of largest FL dilatation, } \\
\text { TAWSS was significantly lower } \\
\text { than that derived from a healthy } \\
\text { aorta, and total pressure in aortic } \\
\text { dissection was lower than in the } \\
\text { healthy aorta. }\end{array}$ \\
\hline Shang et al [12] & 2015 & 14 & CTA images of 14 & Correlation of CFD & High TAWSS was seen in rapidly \\
\hline
\end{tabular}




\begin{tabular}{|c|c|c|c|c|c|}
\hline & & & $\begin{array}{l}\text { patients with acute type } \\
\text { B dissection (7 cases } \\
\text { with stable aortic } \\
\text { diameters and } 7 \text { cases } \\
\text { with expanding } \\
\text { dissecting aneurysms) } \\
\end{array}$ & $\begin{array}{l}\text { simulations with long-term } \\
\text { clinical outcomes in } \\
\text { medically managed and } \\
\text { surgically treated patients. }\end{array}$ & $\begin{array}{l}\text { aortic growth cases, with higher } \\
\text { percentage of flow in the FL. } \\
\text { Greater turbulence flow and higher } \\
\text { velocity flow in the FL in rapidly } \\
\text { expanding aneurysms. }\end{array}$ \\
\hline Tse et al [13] & 2011 & 1 & $\begin{array}{l}\text { CT images of a 38- } \\
\text { year-old female with } \\
\text { chronic type B aortic } \\
\text { dissection }\end{array}$ & $\begin{array}{l}\text { Quantitative analysis of } \\
\text { hemodynamics in pre-and } \\
\text { post aneurysmal dissecting } \\
\text { aorta. }\end{array}$ & $\begin{array}{l}\text { TAWSS was higher in the FL and } \\
\text { high WSS observed at the entry } \\
\text { tear. High pressure was noticed in } \\
\text { the FL in post-aneurysmal model. } \\
\text { Helical nature of hemodynamic } \\
\text { flow was associated with FL } \\
\text { wrapping around the TL. }\end{array}$ \\
\hline $\begin{array}{c}\text { Wan Ab Naim et al } \\
{[14]}\end{array}$ & 2014 & 1 & $\begin{array}{l}\text { CT images of a 59- } \\
\text { year-old male with } \\
\text { acute type B dissection }\end{array}$ & $\begin{array}{l}\text { Impact of number of re-entry } \\
\text { tears on hemodynamic } \\
\text { changes (with simulation of } \\
\text { re-entry tear of } 10 \text { and } 16 \\
\text { mm diameter, respectively). }\end{array}$ & $\begin{array}{l}\text { Presence of additional re-entry tear } \\
\text { led to a decrease in the FL during } \\
\text { systole, with no significant change } \\
\text { in TAWSS. Direction and } \\
\text { magnitude of blood flow were not } \\
\text { changed due to re-entry tear. }\end{array}$ \\
\hline $\begin{array}{c}\text { Wan Ab Naim et al } \\
\text { [15] }\end{array}$ & 2015 & 1 & $\begin{array}{l}\text { CT images of a 59- } \\
\text { year-old male with } \\
\text { acute type B dissection }\end{array}$ & $\begin{array}{l}\text { Vortical structure and its } \\
\text { interaction with WSS to } \\
\text { predict FL formation, with } \\
\text { simulation of increased and } \\
\text { decreased diameters of the } \\
\text { FL. }\end{array}$ & $\begin{array}{l}\text { Vortical structures occupied the } \\
\text { entire FL region. Higher WSS was } \\
\text { associated with increase in FL size, } \\
\text { thus increasing the risk of } \\
\text { thrombus formation and } \\
\text { aneurysmal dilatation. }\end{array}$ \\
\hline Zhang et al [16] & 2014 & 3 & $\begin{array}{c}\text { CT images of a 28- } \\
\text { year-old male healthy } \\
\text { aorta, 62-year-old male } \\
\text { acute type B dissection } \\
\text { with distal tears } \\
\text { involving visceral } \\
\text { arteries and 45-year-old }\end{array}$ & $\begin{array}{l}\text { Wall pressure changes and } \\
\text { effects on longitudinal } \\
\text { propagation of aortic } \\
\text { dissection. }\end{array}$ & $\begin{array}{l}\text { Wall pressure imbalance was } \\
\text { visualised between TL and FL, and } \\
\text { the pressure imbalance was more } \\
\text { significant when there were no } \\
\text { distal tears or side branches. }\end{array}$ \\
\hline
\end{tabular}




\begin{tabular}{|l|l|c|l|l|}
\hline & & $\begin{array}{c}\text { male acute type B } \\
\text { dissection without distal } \\
\text { tears }\end{array}$ & \\
\hline
\end{tabular}

* Details of the selected patient were not available in this study. CFD-computational fluid dynamics, EVAR-endovascular aortic repair, FL-false lumen, OSI-oscillatory shear index, WSS-wall shear stress, TAWSS-time-averaged wall shear stress, TL-true lumen, FSI-fluid structure interaction. 